\title{
Depression and Anxiety among Patients with Type II Diabetes Mellitus in Chitwan Medical College Teaching Hospital, Nepal
}

\author{
Kalpana Sharma $\mathbb{D}^{\mathbb{D}},{ }^{1}$ Govinda Dhungana ${ }^{\mathbb{D}},{ }^{2}$ Shailendra Adhikari, ${ }^{3}$ Archana Bista Pandey, ${ }^{4}$ \\ and Muna Sharma ${ }^{4}$
}

\author{
${ }^{1}$ School of Nursing, Chitwan Medical College Affiliated to Tribhuvan University, Bharatpur 44207, Nepal \\ ${ }^{2}$ Department of Statistics, Birendra Multiple Campus, Tribhuvan University, Bharatpur 44207, Nepal \\ ${ }^{3}$ Department of Psychiatry, Chitwan Medical College Affiliated to Tribhuvan University, Bharatpur 44207, Nepal \\ ${ }^{4}$ Maharajgunj Nursing Campus, Institute of Medicine, Tribhuvan University, Bharatpur 44600, Nepal
}

Correspondence should be addressed to Kalpana Sharma; sharma.kalpana@cmc.edu.np

Received 10 July 2020; Revised 9 December 2020; Accepted 18 December 2020; Published 13 January 2021

Academic Editor: Maria H F Grypdonck

Copyright (c) 2021 Kalpana Sharma et al. This is an open access article distributed under the Creative Commons Attribution License, which permits unrestricted use, distribution, and reproduction in any medium, provided the original work is properly cited.

\begin{abstract}
The prevalence of depression and anxiety disorders is common among people with diabetes mellitus. Coexistence of diabetes and depression/anxiety increases the risk of diabetes complications and reduces the overall quality of life. Hence, this study aimed to assess the depression and anxiety among patients with type 2 diabetes mellitus in Chitwan. Descriptive survey was carried out among 296 purposively selected clinically diagnosed type 2 diabetes patients admitted in the Chitwan Medical College Teaching Hospital from $15^{\text {th }}$ June 2018 to $17^{\text {th }}$ September 2019. Patients were interviewed using the Patient Health Questionnaire-9 (PHQ9) and Generalized Anxiety Disorders-7 (GAD-7). Data were analyzed using descriptive and inferential statistics. Of 296 diabetic patients, $48.6 \%$ were 60 years and above, $59.5 \%$ female and $61.5 \%$ literate; their common occupation was agriculture (38.2\%) followed by household work $(26.4 \%)$. Nearly two-thirds $(62.8 \%)$ of diabetes patients had other chronic comorbid conditions. Depression and anxiety were observed among $57.8 \%$ and $49.7 \%$ of diabetes patients, respectively. While observing the severity, $27.4 \%, 19.6 \%, 8.4 \%$, and $2.4 \%$ of patients had mild, moderate, moderately severe, and severe depression, respectively. Likewise, $24.7 \%, 20.3 \%$, and $4.7 \%$ of patients had mild, moderate, and severe anxiety, respectively. Current living status, educational status, medicine adherence, satisfaction toward current treatment, and history of mental illness in the family were found to be significant factors associated with the anxiety of patients with diabetes. Further, educational status, smoking habit, satisfaction towards current treatment, and history of diabetes in family were the factors associated with depression. Prevalence of depression and anxiety is high among admitted patients with diabetes mellitus, and many factors are associated with it. Hence, regular screening services are essential along with diabetes management plan for timely identification and treatment of the vulnerable groups in the healthcare centers.
\end{abstract}

\section{Introduction}

Diabetes mellitus (DM) is a frequently encountered chronic metabolic disease which is characterized by elevated plasma glucose level resulting from inadequate insulin secretion and/or increased insulin resistance. According to the International Diabetes Federation (IDF), there were estimated 463 million adults, 20-79 years, living with diabetes mellitus in 2019 which accounted for $9.3 \%$ of the global population and was expected to increase to $10.2 \%$ (578 million) by 2030 and $10.9 \%$ (700 million) by 2045 . Although the proportion of people with type 2 diabetes is increasing in most countries, $79 \%$ of adults with diabetes are living in low- and middleincome countries [1] and the expected rise in prevalence will be more aggressive in low-income countries [2]. People with DM have a higher risk of morbidity and mortality as well as increased healthcare cost than the general population. Diabetes caused 4.2 million deaths and at least $10 \%$ of global health expenditure in 2019 (USD 760 billion dollars) (IDF, 2019) [1]. In Nepal, DM is emerging as a major health 
problem and its prevalence accounts for $8.4 \%$ among adults. The prevalence of diabetes is reported to be higher in urban than in rural areas [3].

Diabetes is typically a manageable disease through lifestyle modifications and treatment. However, it can create added stress to the diabetes patients due to the never-ending demands of diabetes care, such as eating and maintaining physical health, exercising, monitoring blood glucose, regular follow-up, and management of symptoms and fears about or the reality of complications. As a result, they experience feelings of depression, anxiety, and stress, which affect their health and overall quality of life [4].

During psychological stress, counter-regulatory hormones such as catecholamine, a neurotransmitter, glucocorticoids, growth hormones, and glucagon are activated [5]. The activation of the counter regulatory hormones interferes in the action of insulin which is not able to lower glucose but instead elevates blood glucose. The increase in glucose level creates a greater challenge in maintaining metabolic control. Poor glycemic control and functional impairment due to increasing diabetes complications may cause or worsen depression [6] and anxiety in patients [7, 8].

Anxiety and depression are common among patients suffering from type II diabetes, and their prevalence has been summarized in a number of studies [7, 9-11]. Patients with diabetes had significantly higher anxiety and depression than general population $[12,13]$. The coexistence of diabetes and depression results in poor glycemic control and self-management, increases the risk of diabetes complications, and reduces overall quality of life and life expectancy $[10,14-16]$. So, prevention, early recognition, and treatment of these conditions are essential for achieving optimal goals in the management and in patients' overall quality of life.

In Nepal, depression and anxiety are usually underdiagnosed and undertreated due to social stigma and discrimination as well as there is a dearth in the literatures related to topic. Few previous studies [9, 17-19] reported depression among patients with type II diabetes mellitus attending outpatients' settings. Hence, this study was undertaken to find out depression and anxiety among admitted patients with type II diabetes mellitus which will be helpful for the healthcare providers to plan collaborative care in healthcare settings.

\section{Materials and Methods}

Descriptive cross-sectional survey design was used, and the study was conducted in the Chitwan Medical College Teaching Hospital (CMC-TH), Bharatpur-10, Chitwan, from $15^{\text {th }}$ June 2018 to $17^{\text {th }}$ September 2019. Population of the study was those clinically diagnosed type II diabetes patients either alone or in combination with other diseases admitted in medicine inpatient departments of CMC-TH. Those patients who were clinically diagnosed with type II diabetes according to International Diabetes Federation (IDF) criteria for at least one year irrespective of their sex were included in the study, whereas patients who were unable to complete the interview due to communication or cognitive difficulties were excluded. Sample size was determined using $40.3 \%$ overall prevalence of depression among type 2 diabetes at tertiary care centers of Kathmandu [9] with an allowable error of $6 \%$ at $95 \%$ confidence interval. The estimated sample size was 296 after adding 15\% nonresponse rate. A purposive sampling technique was used to select the desired sample for the study.

Pretested Nepali version structured interview schedule was used to collect the sociodemographic and disease-related information of the patients. The Patient Health Questionnaire-9 (PHQ-9) and Generalized Anxiety Disorders-7 (GAD-7) were used for the screening of depression and anxiety. These two instruments assessed the symptoms experienced by participants during the 2 -week period before they take the survey. Each item of GAD-7 and PHQ-9 was rated 0 to 3 scores, where 0 -not at all, 1-several days, 2-more than half of the days, and 3-nearly every day, with higher scores indicating patients' increased self-report of anxiety and depression severity. The PHQ-9 questionnaire is a validated questionnaire, found to be useful in screening of patients for psychiatric illness worldwide [20-25]. Content and face validity was established through extensive literature review and consultation with experts. Pretesting of the Nepali version instrument was done among 50 diabetes patients admitted in the CMC-TH, and they were excluded from the final study. Reliability of the instrument was tested by calculating Cronbach's alpha values of PHQ-9 and GAD7 which were 0.78 and 0.75 , respectively.

Data were collected through the face-to-face interview method on the $2^{\text {nd }}$ day of admission in a separate room. Scores obtained in GAD-7 were classified into mild (5-9), moderate (10-14), and severe anxiety $(\geq 15)$. Likewise, scores of PHQ-9 were divided into mild $(5$ to $<10)$, moderate (10 to $<15)$, moderately severe $(15$ to $<20)$, and severe $(\geq 20)$ depression. Those patients who had moderate-to-severe anxiety and depression were referred to the psychiatry department for further management.

To maintain the rights of patients, further evaluation was performed by psychiatrists to those patients who were found to be positive on PHQ-9 and GAD-7 for confirmation and further treatment. Ethical approval was obtained from the Chitwan Medical College Institutional Review Committee (CMC-IRC). Written informed consent was obtained from the patients ensuring their confidentiality of the information.

Collected data were entered into IBM SPSS (Statistical Package for Social Sciences) version 20. Then, data were analyzed in terms of descriptive statistics as well as bivariate analysis. Statistical significance was determined at $p<0.05$. Then, a multivariate logistic regression model was designed for those variables significant at the bivariate level.

\section{Results}

Of 296 patients, nearly half (48.6\%) were 60 years and above and more than half (59.5\%) were female. Majority ( $84.8 \%)$ of the patients followed Hinduism, 68.6\% were urban residents, $62.5 \%$ belonged to joint family, and nearly two-thirds $(61.5 \%)$ were literate. Common occupation was agriculture 
(38.2\%) and household work (26.4\%). More than two-thirds $(68.2 \%)$ of the patients reported that they quit their job due to their illness. Approximately half (49.7\%) of the patients reported that their monthly family income was just sufficient for their daily expenses and $25.3 \%$ reported surplus expenses (Table 1).

Regarding clinical variables, more than one-third (37.2\%) of the patients had diabetes only, whereas $62.8 \%$ had diabetes with other comorbidities. More than three-fourths (76.4\%) of the patients' duration of diagnosis was $\geq 3$ years, $53.7 \%$ had no history of hospital admission in the last one year, $86.8 \%$ had adherence with their medicine, $87.2 \%$ were satisfied with their treatment, and only $9.5 \%$ had a family history of mental illness (Table 2).

In diabetes patients, overall depression was seen among $57.8 \%$ of patients. Among them, 27.4\% had mild depression, $19.6 \%$ had moderate depression, $8.4 \%$ had moderately severe depression, and $2.4 \%$ had severe depression. Likewise, overall, $49.7 \%$ of patients had anxiety disorder where $24.7 \%$, $20.3 \%$, and $4.7 \%$ of patients had mild, moderate, and severe anxiety, respectively (Table 3 ).

Table 4 shows that the level of anxiety disorder was significantly associated with the sociodemographic variables such as current living status $(p=0.001)$ and educational status $(p=0.001)$ of the diabetic patients. Likewise, level of depression was significantly associated with the age group in years $(p=0.045)$, current living status $(p=0.003)$, educational status $(p=<0.001)$, smoking habit $(p=0.005)$, and perceived impact of illness on work $(p=0.014)$.

In Table 5, significant association was found between level of anxiety and selected disease-related variables such as medication adherence $(p=0.003)$, satisfaction towards current treatment $(p<0.001)$, and history of mental problem in family ( $p=0.001)$. Likewise, level of depression was significantly associated with satisfaction towards current treatment $(p=0.013)$, other comorbidities $(p=0.037)$, history of diabetes in family $(p=<0.001)$, and history of mental problem in the family $(p=0.019)$ (Table 5).

Logistic regression analysis showed that patients who were currently living with the family, were illiterate, had nonadherence to medication, had a family history of mental diseases, and were not satisfied with current treatment were more likely to be affected by anxiety compared to patients who lived alone, were literate, had adherence to medication, had no history of mental diseases in family, and were satisfied towards current treatment (Table 6).

Regarding depression, patients who were not satisfied towards current treatment, were illiterate, were smokers, and had a family history of diabetes were more likely to have depression than patients who were satisfied with treatment, were illiterate, were never smokers, and had no history of diabetes in the family (Table 7).

\section{Discussion}

This study assessed the depression and anxiety among patients with type 2 diabetes mellitus admitted in a tertiary care
TABLE 1: Sociodemographic characteristics of patients.

\begin{tabular}{|c|c|}
\hline Sociodemographic characteristics & $\begin{array}{c}n=296 \\
\text { Number } \\
(\%)\end{array}$ \\
\hline $\begin{array}{l}\text { Age groups in years } \\
\quad<40 \\
40-60 \\
\geq 60 \\
\text { Mean } \pm S D=59.50 \pm 11.72 \text {; min. age: } 25 \text { years; } \\
\text { max. age: } 90\end{array}$ & $\begin{aligned} 12 & (4.1) \\
140 & (47.3) \\
144 & (48.6)\end{aligned}$ \\
\hline $\begin{array}{l}\text { Sex } \\
\quad \text { Female } \\
\text { Male } \\
\end{array}$ & $\begin{array}{l}178(59.5) \\
120(40.5)\end{array}$ \\
\hline $\begin{array}{l}\text { Religion } \\
\text { Hindu } \\
\text { Other than } \mathrm{Hindu}^{\odot}\end{array}$ & $\begin{array}{cc}251 & (84.8) \\
45 & (15.2)\end{array}$ \\
\hline $\begin{array}{l}\text { Caste } \\
\text { Bramin } \\
\text { Chhetri } \\
\text { Janajati } \\
\text { Dalit and Madhesi }\end{array}$ & $\begin{array}{c}99(33.4) \\
47(15.9) \\
117(39.5) \\
33(11.1) \\
\end{array}$ \\
\hline $\begin{array}{c}\text { Residence } \\
\text { Rural } \\
\text { Urban } \\
\end{array}$ & $\begin{array}{l}93(31.4) \\
203(68.6) \\
\end{array}$ \\
\hline $\begin{array}{l}\text { Family type } \\
\text { Nuclear } \\
\text { Joint }\end{array}$ & $\begin{array}{l}111(37.5) \\
185(62.5) \\
\end{array}$ \\
\hline $\begin{array}{l}\text { Marital status } \\
\text { Unmarried } \\
\text { Married (husband/wife together) } \\
\text { Widow/widower } \\
\text { Divorce and others }\end{array}$ & $\begin{array}{c}5(1.7) \\
243(82.3) \\
46(15.5) \\
2(0.7)\end{array}$ \\
\hline $\begin{array}{l}\text { Current living status } \\
\text { Alone } \\
\text { With family } \\
\end{array}$ & $\begin{array}{c}37(12.5) \\
259(87.5)\end{array}$ \\
\hline $\begin{array}{l}\text { Educational level } \\
\text { Illiterate } \\
\text { Literate } \\
\text { Primary } \\
\text { Secondary and above } \\
\end{array}$ & $\begin{array}{c}114(38.5) \\
118(39.9) \\
33(11.1) \\
31(10.5) \\
\end{array}$ \\
\hline $\begin{array}{l}\text { Occupation } \\
\text { Agriculture } \\
\text { Household work } \\
\text { Service } \\
\text { Business } \\
\text { Others (daily wages) } \\
\end{array}$ & $\begin{array}{l}113(38.2) \\
78(26.4) \\
48(16.2) \\
32(10.8) \\
25(8.5)\end{array}$ \\
\hline $\begin{array}{l}\text { Family income } \\
\text { Insufficient } \\
\text { Just sufficient } \\
\text { Surplus } \\
\end{array}$ & $\begin{array}{c}74(25.0) \\
147(49.7) \\
75(25.3) \\
\end{array}$ \\
\hline $\begin{array}{l}\text { Impact of illness to quit the job } \\
\text { Yes } \\
\text { No }\end{array}$ & $\begin{array}{c}94(31.8) \\
202(68.2)\end{array}$ \\
\hline
\end{tabular}

${ }^{\odot}$ Including Buddhists, Christians, Muslims, Kirats, and others.

center of Chitwan. Of 296 patients with type 2 diabetes mellitus, more than half $(57.8 \%)$ of the patients exhibited depression and nearly half (49.7\%) showed generalized anxiety disorders. Many variables are associated with the level of depression and anxiety of the patients. 
TABle 2: Disease-related characteristics of patients.

\begin{tabular}{lc}
\hline & $n=296$ \\
\hline Variables & Number \\
Presence of comorbidity & $110(37.2)$ \\
$\quad$ No & $186(62.8)$ \\
Yes & \\
Number of comorbidities & $110(37.2)$ \\
$\quad$ None & $105(35.4)$ \\
$\quad$ One & $81(27.4)$ \\
Two or more & \\
Duration of disease diagnosis in years & $70(23.6)$ \\
$\quad<3$ years & $226(76.4)$ \\
$\geq 3$ years & \\
Number of hospital admissions in the last 1 year \\
( $n=926)$ \\
$\quad$ None & $159(53.7)$ \\
$\quad<3$ & $91(30.7)$ \\
$3-4$ & $46(15.5)$ \\
Medicine adherence & \\
$\quad$ Yes & $257(86.8)$ \\
No & $39(13.2)$ \\
Satisfaction toward current treatment & \\
Yes & $258(87.2)$ \\
No & $38(12.8)$ \\
H/o diabetes in family & \\
Yes & $125(42.2)$ \\
No & $171(57.8)$ \\
H/o mental problem in family & \\
Yes & $28(9.5)$ \\
No & $268(90.5)$ \\
\hline
\end{tabular}

TABLE 3: Level of depression and anxiety among patients with diabetes mellitus.

\begin{tabular}{lc}
\hline Variables & $n=296$ \\
Lumber $(\%)$
\end{tabular}

The prevalence of depression in our sample is almost similar to the studies conducted among T2DM patients in Kathmandu, Nepal, i.e., 40.3\% [9] and 44.1\% [19] but higher than the prevalence reported among the patients in Sunsari district (22.7\%) [17]. Regarding severity of depression, $27.4 \%, 14.6 \%, 8.4 \%$, and $2.4 \%$ of patients had mild, moderate, moderately severe, and severe depression, respectively. Although data related to severity from Nepal are limited, a study in Saudi Arabia showed mild, moderate, severe, and extremely severe depression among 9.3\%, $14.0 \%, 7.1 \%$, and $3.3 \%$ of patients with type $2 \mathrm{DM}$, respectively [10].
Compared to other published studies, our finding is almost similar to the study in Pakistan which revealed $49.2 \%$ depression in patients with DM [8]. However, prevalence of depression is higher in our sample than that in the studies conducted in Jordan [25], South London King's College hospital [26], Palestine [27], Saudi Arabia [28], and NorthEastcoast Malaysia [29]. Similarly, a meta-analysis of 42 published studies held in the United States reported the prevalence of major depression among $11 \%$ of diabetic patients and the prevalence of clinically serious depression in $31 \%$ of patients [30]. Likewise, a study carried out in Jordan revealed that the prevalence rate of undiagnosed depression among Jordanian diabetic patients was $19.7 \%$ [31]. The possible reasons for the varied prevalence rate of depression in studies might be the use of different scales to screen the depressive symptoms in patients and settings used in these studies.

Along with depression, anxiety is also common among diabetes patients and many studies have reported about it. In our study, half $(49.7 \%)$ of the patients had anxiety disorders where mild, moderate, and severe anxiety was found in $24.7 \%, 20.3 \%$, and $4.7 \%$ of patients, respectively. Similar results were also reported by studies conducted in Pakistan [8], Saudi Arabia [10, 28], South London King's College hospital [26], and Jordan [25], which found 50.7\%, $43.4 \%, 42.0 \%, 38.3 \%$, and $37.7 \%$ anxiety, respectively, in patients with DM. Our finding is slightly higher than the finding reported by the study in India which showed overall prevalence of anxiety among $34 \%$ of patients where mild, moderate, and severe anxiety was found in $22 \%, 8 \%$, and $4 \%$, of patients, respectively, by GAD-7 scale [24]. In the same line, a study in Saudi Arabia showed mild, moderate, severe and extremely severe anxiety among 13.4, 13.0\%, $6.0 \%$, and $5.8 \%$ of patients with type $2 \mathrm{DM}$, respectively [10]. However, very low prevalence of anxiety was observed in other studies conducted in 15 nations [32] and in United States, Baltimore [33] which showed $18.0 \%$ and $21.8 \%$ overall prevalence of anxiety respectively among type 2 diabetes patients. The variation in the results might be due to nature of the patients included in these studies and different measurement tools.

Bivariate analysis of this study found the significant association of depression with other selected variables such as age in year, current living status, educational status, impact of illness on work, smoking habit, satisfaction towards current treatment, presence of comorbidities, history of diabetes in family, and history of mental problem in family. Regression analysis also found educational status, smoking status, satisfaction toward current treatment, and history of diabetes in family as significant factors associated with depression in the model. These findings are in line with other studies that highlighted the association of depression with patients' educational status, smoking status, family history of diabetes, and compliance with diabetes management $[9,17,19,25]$. In our study, age and presence of other chronic comorbidities were not significant to the regression model, whereas Ahmad and colleagues reported the significant association of age and presence of $\geq$ three comorbid diseases than their counterparts in Jordan [25]. 
TABLE 4: Association between anxiety and depression with selected sociodemographic and behavioral pattern of patients.

\begin{tabular}{|c|c|c|c|c|c|c|c|c|}
\hline \multirow{2}{*}{ Variables } & \multicolumn{2}{|c|}{ Anxiety } & \multirow{2}{*}{$x^{2}$} & \multirow{2}{*}{$p$ value } & \multicolumn{2}{|c|}{ Depression } & \multirow{2}{*}{$x^{2}$} & \multirow{2}{*}{$\begin{array}{l}n=296 \\
p \text { value }\end{array}$} \\
\hline & No & Yes & & & No & Yes & & \\
\hline \multicolumn{9}{|l|}{ Age group in year } \\
\hline$<40$ & $10(58.8)$ & $7(41.2)$ & \multirow{3}{*}{1.122} & \multirow{3}{*}{0.571} & $12(70.6)$ & $5(29.4)$ & \multirow{3}{*}{6.221} & \multirow{3}{*}{0.045} \\
\hline $40-60$ & $72(47.7)$ & $79(52.3)$ & & & $59(39.1)$ & $92(60.9)$ & & \\
\hline$\geq 60$ & $67(52.3)$ & $61(47.7)$ & & & $54(42.2)$ & $74(57.8)$ & & \\
\hline \multicolumn{9}{|l|}{ Sex } \\
\hline Female & $93(52.8)$ & $83(47.2)$ & \multirow[t]{2}{*}{1.088} & \multirow[t]{2}{*}{0.297} & $71(40.3)$ & $105(59.7)$ & \multirow[t]{2}{*}{0.635} & \multirow[t]{2}{*}{0.426} \\
\hline Male & $56(46.7)$ & $64(53.3)$ & & & $54(45.0)$ & $66(55.0)$ & & \\
\hline \multicolumn{9}{|l|}{ Residence } \\
\hline Rural & $53(57.0)$ & $40(43.0)$ & \multirow[b]{2}{*}{2.400} & \multirow[b]{2}{*}{0.121} & $45(48.4)$ & $48(51.6)$ & \multirow{2}{*}{2.107} & \multirow{2}{*}{0.147} \\
\hline Urban & $96(47.3)$ & $107(52.7)$ & & & $80(39.4)$ & $123(60.6)$ & & \\
\hline \multicolumn{9}{|l|}{ Family type } \\
\hline Nuclear & $58(52.3)$ & $53(47.7)$ & \multirow[t]{2}{*}{0.260} & \multirow[t]{2}{*}{0.610} & $48(43.2)$ & $63(56.8)$ & \multirow[t]{2}{*}{0.075} & 0.785 \\
\hline Joint & $91(49.2)$ & $94(50.8)$ & & & $77(41.6)$ & $108(58.4)$ & & \\
\hline Current living status & & & & & & & & \\
\hline Single & $28(75.7)$ & $9(24.3)$ & 10.860 & 0.001 & $24(64.9)$ & $13(35.1)$ & 8.880 & 0.003 \\
\hline With family & $121(46.7)$ & $138(53.3)$ & & & $101(39.0)$ & $158(61.0)$ & & \\
\hline Educational status & & & & & & & & \\
\hline Illiterate & $44(38.6)$ & $70(61.4)$ & 10.224 & 0.001 & $33(28.9)$ & $81(71.1)$ & 13.408 & $<0.001$ \\
\hline Literate & $105(57.7)$ & $77(42.3)$ & & & $92(50.5)$ & $90(49.5)$ & & \\
\hline Occupation & & & & & & & & \\
\hline Agriculture & $54(47.8)$ & $59(52.2)$ & & & $43(38.1)$ & $70(61.9)$ & & \\
\hline Homemade work & $43(55.1)$ & $35(44.9)$ & 1.800 & 0.615 & $34(43.6)$ & $44(56.4)$ & 1.984 & 0.576 \\
\hline Service & $26(54.2)$ & $22(45.8)$ & & & $20(41.7)$ & $28(58.3)$ & & \\
\hline Business and others & $26(45.6)$ & $31(54.4)$ & & & $28(49.1)$ & $29(50.9)$ & & \\
\hline Family income & & & & & & & & \\
\hline Insufficient & $35(47.3)$ & $39(52.7)$ & 2.006 & 0.367 & $30(40.5)$ & $44(59.5)$ & 1.499 & 0.473 \\
\hline Just sufficient & $80(54.4)$ & $67(45.6)$ & & & $67(45.6)$ & $80(54.4)$ & & \\
\hline Surplus & $34(45.3)$ & $41(54.7)$ & & & $28(37.3)$ & $47(62.7)$ & & \\
\hline Impact of illness on wc & & & & & & & & \\
\hline Yes & $46(48.9)$ & $48(51.1)$ & 0.108 & 0.742 & $30(31.9)$ & $64(68.1)$ & 6.007 & 0.014 \\
\hline No & $103(51.0)$ & $99(49.0)$ & & & $95(47.0)$ & $107(53.0)$ & & \\
\hline Smoking habit & & & & & & & & \\
\hline Smoking & $14(58.3)$ & $10(41.7)$ & 0.949 & 0.622 & $8(33.3)$ & $16(66.7)$ & 10.546 & 0.005 \\
\hline Past smoker & $49(47.6)$ & $54(52.4)$ & & & $32(31.1)$ & $71(68.9)$ & & \\
\hline Never & $86(50.9)$ & $83(49.1)$ & & & $85(50.3)$ & $84(49.7)$ & & \\
\hline
\end{tabular}

Regarding anxiety, our study found the significant association between anxiety and other variables such as current living status, educational status, satisfaction towards current treatment, medicine adherence, and history of mental problem in family. Furthermore, these variables were identified as significant factors associated with anxiety in the regression analysis model. Similarly, another study also showed the consistent results where anxiety was associated with family history of chronic diseases and compliance with diabetes management [10]. However, Ahmad et al. revealed contrasting results where educational level was not significantly associated with the anxiety of patients [25]. In our study, comorbidity was not significant in bivariate analysis as well as regression model, whereas other studies reported the positive association between anxiety and presence of comorbid diseases $[10,26]$. This difference in results might be due to varied nature of healthcare systems of the countries and nature of patients included in the study.

This study adds to the dearth of information available regarding anxiety and depression among hospitalized patients with type 2 diabetes mellitus in Nepal. Despite this, it has certain limitations: (i) it is a cross-sectional study which could not explore the causal relationship between anxiety and depression with other associated factors; (ii) this study was conducted among diabetes patients who were admitted in tertiary care hospital setting which may itself mean higher anxiety and depression; (iii) it did not exclude the patients with chronic complications which might have influenced the study findings. Considering these limitations, this study suggested that the coexisting anxiety and depression in diabetes patients needs to be screened regularly in the healthcare settings to enhance the efficacy of treatment regimens and reduce an additional burden on diabetes patients. 
TABLE 5: Association between anxiety and depression with selected disease-related variables of patients.

\begin{tabular}{|c|c|c|c|c|c|c|c|c|}
\hline \multirow{2}{*}{ Variables } & \multicolumn{2}{|c|}{ Level of anxiety } & \multirow{2}{*}{$x^{2}$} & \multirow{2}{*}{$p$ value } & \multicolumn{2}{|c|}{ Level of depression } & \multirow{2}{*}{$x^{2}$} & \multirow{2}{*}{$\begin{array}{l}n=296 \\
p \text { value }\end{array}$} \\
\hline & No & Yes & & & No & Yes & & \\
\hline \multicolumn{9}{|c|}{ Duration of disease } \\
\hline$<3$ years & $34(48.6)$ & $36(51.4)$ & 0.114 & 0.735 & $36(51.4)$ & $34(48.6)$ & 3.180 & 0.075 \\
\hline$\geq 3$ years & $115(50.9)$ & $111(49.1)$ & & & $89(39.4)$ & $137(60.6)$ & & \\
\hline \multicolumn{9}{|c|}{ Number of hospital admissions } \\
\hline None & $80(50.3)$ & $79(49.7)$ & 2.274 & 0.321 & $62(39.0)$ & $97(61.0)$ & 2.732 & 0.255 \\
\hline$<3$ & $53(47.3)$ & $59(52.7)$ & & & $49(43.8)$ & $63(56.2)$ & & \\
\hline 34 & $16(64.0)$ & $9(36.0)$ & & & $14(56.0)$ & $11(44.0)$ & & \\
\hline \multicolumn{9}{|c|}{ Medicine adherence } \\
\hline Yes & $138(53.7)$ & $119(46.3)$ & 8.802 & 0.003 & $111(43.2)$ & $146(56.8)$ & 0.738 & 0.390 \\
\hline No & $11(28.2)$ & $28(71.8)$ & & & $14(35.9)$ & $25(64.1)$ & & \\
\hline \multicolumn{9}{|c|}{ Satisfaction toward current treatment } \\
\hline Yes & $140(54.3)$ & $118(45.7)$ & 12.389 & $<0.001$ & $116(45.0)$ & $142(55.0)$ & 6.146 & 0.013 \\
\hline No & $9(23.7)$ & $29(76.3)$ & & & $9(23.7)$ & $29(76.3)$ & & \\
\hline \multicolumn{9}{|c|}{ Presence of comorbidity } \\
\hline No & $61(55.5)$ & $49(44.5)$ & 1.833 & 0.176 & $55(50.0)$ & $55(50.0)$ & 4.332 & 0.037 \\
\hline Yes & $88(47.3)$ & $98(52.7)$ & & & $70(37.6)$ & $116(62.4)$ & & \\
\hline \multicolumn{9}{|c|}{ Number of comorbidities } \\
\hline None & $61(55.5)$ & $49(44.5)$ & 2.460 & 0.292 & $55(50.0)$ & $55(50.0)$ & 4.538 & 0.103 \\
\hline One & $47(44.8)$ & $58(55.2)$ & & & $38(36.2)$ & $67(63.8)$ & & \\
\hline Two or more & $41(50.6)$ & $40(49.4)$ & & & $32(39.5)$ & $49(60.5)$ & & \\
\hline \multicolumn{9}{|c|}{ H/o diabetes in family } \\
\hline Yes & $65(52.0)$ & $60(48.0)$ & 0.239 & 0.625 & $37(29.6)$ & $88(70.4)$ & 14.147 & $<0.001$ \\
\hline No & $84(49.1)$ & $87(50.9)$ & & & $88(51.5)$ & $83(48.5)$ & & \\
\hline \multicolumn{9}{|c|}{ H/o mental problem in family } \\
\hline Yes & $6(21.4)$ & $22(78.6)$ & 10.339 & 0.001 & $6(21.4)$ & $22(78.6)$ & 5.485 & 0.019 \\
\hline No & $143(53.4)$ & $125(46.6)$ & & & $119(44.4)$ & $149(55.6)$ & & \\
\hline
\end{tabular}

TABLE 6: Factors associated with the anxiety of patients.

\begin{tabular}{|c|c|c|c|c|c|}
\hline Variables & Unadjusted OR & $p$ & Adjusted OR & $p$ & $\begin{array}{l}n=296 \\
95 \% \text { CI }\end{array}$ \\
\hline Educational status (1-illiterate, 0 -literate) & 2.169 & 0.002 & 2.192 & 0.003 & $1.318-3.646$ \\
\hline Current living status (1-with family, 0 -single) & 3.548 & 0.002 & 3.098 & 0.008 & $1.340-7.164$ \\
\hline Medication adherence (1-non-adherence, 0 -Adherence) & 2.952 & 0.004 & 2.791 & 0.010 & $1.273-6.122$ \\
\hline Satisfaction towards current treatment (1-no, 0 -yes) & 3.823 & 0.001 & 3.744 & 0.002 & $1.619-8.662$ \\
\hline Mental problem in family (1-yes, 0 -no) & 4.195 & 0.003 & 2.895 & 0.034 & $1.081-7.755$ \\
\hline
\end{tabular}

Dependent variable: anxiety; Nagelkerke $R^{2}=0.196$. OR: odds ratio.

TABLE 7: Factors associated with the depression of patients.

\begin{tabular}{|c|c|c|c|c|c|}
\hline Variables & Unadjusted OR & $p$ & Adjusted OR & $p$ & $\begin{array}{l}n=296 \\
95 \% \text { CI }\end{array}$ \\
\hline Educational status (1-illiterate, 0 -literate) & 2.509 & 0.001 & 2.581 & 0.001 & $1.487-4.481$ \\
\hline Current living status (1-with family, 0 -single) & 2.888 & 0.004 & 1.335 & 0.502 & $0.574-3.104$ \\
\hline Smoking status (1-smoker, 0 -never smoker) & 2.201 & 0.001 & 2.072 & 0.007 & $1.221-3.516$ \\
\hline Impact of illness on work (1-yes, 0 -no) & 1.894 & 0.015 & 1.392 & 0.261 & $0.782-2.479$ \\
\hline Presence of comorbidity (1-yes, 0 -no) & 1.657 & 0.038 & 1.520 & 0.132 & $0.881-2.621$ \\
\hline Satisfaction towards current treatment (1-no, 0 -yes) & 2.632 & 0.016 & 3.293 & 0.009 & $1.352-8.018$ \\
\hline History of DM in family (1-yes, 0 -no) & 2.522 & 0.006 & 2.181 & 0.006 & $1.253-3.797$ \\
\hline $\mathrm{H} / \mathrm{o}$ mental problem in family ( 1 -yes, 0 -no) & 2.928 & 0.024 & 1.633 & 0.340 & $0.593-4.542$ \\
\hline
\end{tabular}

Dependent variable: depression; Nagelkerke $R^{2}=0.217$. OR: odds ratio. 


\section{Conclusions}

Depression and anxiety are high among the admitted patients suffering from type 2 diabetes mellitus. Many factors such as educational status, current living status, smoking status, medication adherence, satisfaction toward current treatment, and history of mental problem in the family are associated with anxiety and depression. Hence, there is a need to develop an integrated care model to manage these morbidities associated with diabetes mellitus.

\section{Recommendations}

Routine screening and counselling by nurses working in medical departments and regular visits by psychiatrists are recommended for the early detection and treatment of anxiety and depression among diabetes patients admitted in healthcare settings. Many factors are associated with anxiety and depression so these factors are needed to be considered while planning and implementing the program for the risk groups.

\section{Data Availability}

The datasets used and/or analyzed during the current study are available from the corresponding author upon request.

\section{Ethical Approval}

Ethical approval was obtained from the Chitwan Medical College Institutional Review Committee (CMC-IRC).

\section{Consent}

Participants were enrolled after obtaining written informed consent.

\section{Conflicts of Interest}

The authors declare that there are no conflicts of interest.

\section{Authors' Contributions}

KS provided the concept, designed and executed the study, interpreted the data, and prepared the report of the study. SA provided an input on concept design and collection of data for the study. GD contributed to data management and analysis. APB and MS contributed to report preparation. All authors read and approved the final paper.

\section{Acknowledgments}

The authors thank the management of Chitwan Medical College, Department of Medicine and Psychiatry, for their kind cooperation during data collection period. The authors are also grateful to University Grant Commission for financial support. Last but not least, the authors are thankful to all participants, for their kind support and participation. This study was supported by the University Grant Commission, Sanothimi, Bhaktapur, as a faculty research project.

\section{References}

[1] International Diabetes Federation, "Diabetes facts and figures," Diabetes Atlas, International Diabetes Federation, Brussels, Belgium, 2019, https://www.idf.org/aboutdiabetes/ what-is-diabetes/facts-figures.html, 9th edition.

[2] A. B. Kaiser, N. Zhang, and W. van der Pluijm, "Global prevalence of type 2 diabetes over the next ten years (2018-2028)," Diabetes, vol. 67, no. 1, p. 202, 2018.

[3] B. Gyawali, R. Sharma, D. Neupane, S. R. Mishra, E. van Teijlingen, and P. Kallestrup, "Prevalence of type 2 diabetes in Nepal: a systematic review and meta-analysis from 2000 to 2014," Global Health Action, vol. 8, Article ID 29088, 2015.

[4] S. Penckofer, C. E. Ferrans, B. Velsor-Friedrich, and S. Savoy, "The psychological impact of living with diabetes: women's day-to-day experiences," The Diabetes Educator, vol. 33, no. 4, pp. 680-690, 2007.

[5] J. E. Grisel, P. R. Rasmussen, and L. Sperry, "Anxiety and depression: physiological and pharmacological considerations," The Journal of Individual Psychology, vol. 62, no. 4, pp. 398-416, 2006.

[6] P. J. Lustman and R. E. Clouse, "Depression in diabetic patients: the relationship between mood and glycemic control," Journal of Diabetes and Its Complications, vol. 19, no. 2, pp. 113-122, 2005.

[7] Y. P. S. Balhara and R. Sagar, "Correlates of anxiety and depression among patients with type 2 diabetes mellitus," Indian Journal of Endocrinology and Metabolism, vol. 15, no. 5, pp. 50-54, 2011.

[8] P. Khan, N. Qayyum, F. Malik et al., "Incidence of anxiety and depression among patients with type 2 diabetes and the predicting factors," Cereus, vol. 11, no. 3, Article ID e4254, 2019.

[9] K. Niraula, B. A. Kohrt, M. S. Flora et al., "Prevalence of depression and associated risk factors among persons with type-2 diabetes mellitus without a prior psychiatric history: a cross-sectional study in clinical settings in urban Nepal," BMC Psychiatry, vol. 13, p. 309, 2013.

[10] A. Alzahrani, A. Alghamdi, T. Alqurni, R. Alshareef, and A. Alzahrani, "Prevalence and predictors of depression, anxiety, and stress symptoms among patients with type II diabetes attending primary healthcare centers in the western region of Saudi Arabia: a cross-sectional study," International Journal of Mental Health Systems, vol. 13, no. 48, 2019.

[11] G. Kaur, G. H. Tee, S. Ariaratnam, A. S. Krishnapillai, and K. China, "Depression, anxiety and stress symptoms among diabetics in Malaysia: a cross sectional study in an urban primary care setting," BMC Family Practice, vol. 14, no. 1, p. 69, 2013.

[12] R. Rajput, P. Gehlawat, and M. Rajput, "Prevalence and predictors of depression and anxiety in patients of diabetes mellitus in a tertiary care center," Indian Journal of Endocrinology and Metabolism, vol. 20, no. 6, pp. 740-751, 2016.

[13] K. J. Smith, M. Béland, M. Clyde et al., "Association of diabetes with anxiety: a systematic review and meta-analysis," Journal of Psychosomatic Research, vol. 74, no. 2, pp. 89-99, 2013.

[14] L. L. Sumlin, T. J. Garcia, S. A. Brown et al., "Depression and adherence to lifestyle changes in type 2 diabetes: a systematic review," The Diabetes Educator, vol. 40, no. 6, 2014.

[15] R. I. G. Holt and W. J. Katon, "Dialogue on diabetes and depression: dealing with the double burden of co-morbidity," Journal of Affective Disorders, vol. 142, pp. S1-S3, 2012. 
[16] G. C. Brown, M. M. Brown, S. Sharma, H. Brown, M. Gozum, and P. Denton, "Quality of life associated with diabetes mellitus in an adult population," Journal of Diabetes and Its Complications, vol. 14, no. 1, pp. 8-24, 2000.

[17] K. A. Sunny, K. V. Khanal, B. R. Sah, and A. Ghimire, "Depression among people living with type 2 diabetes in an urbanizing community of Nepal," PLoS One, vol. 14, no. 6, Article ID e0218119, 2019.

[18] P. Yonzon, A. Joshi, and M. Ghimire, "Prevalence of depression among Nepalese patients with type 2 Diabetes attending endocrine clinic in Kathmandu, Nepal," Diabetes, vol. 67 , no. 1, 2018.

[19] S. Joshi, R. R. Dhungana, and K. U. Subba, "Illness perception and depressive symptoms among persons with type 2 diabetes mellitus: an analytical cross-sectional study in clinical settings in Nepal," Journal of Diabetes Research, vol. 2015, Article ID 908374, 9 pages, 2015.

[20] A. Barua, G. Jacob, and S. Mahmood, "Patient health questionnaire for screening psychiatric disorders in secondary healthcare," Indian Journal of Psychiatry, vol. 55, no. 2, p. 125, 2013.

[21] K. Kroenke, R. L. Spitzer, J. B. W. Williams, and B. Löwe, “The patient health questionnaire somatic, anxiety, and depressive symptom scales: a systematic review," General Hospital Psychiatry, vol. 32, no. 4, pp. 345-359, 2010.

[22] V. Kulkarni, P. Chinnakali, T. Kanchan, A. Rao, M. Shenoy, and M. K. Papanna, "Psychiatric co-morbidities among patients with select non-communicable diseases in a coastal city of South India," International Journal of Preventive Medicine, vol. 5, no. 9, pp. 1139-1145, 2014.

[23] N. Taneja, M. Adhikary, S. Chandramouleeswaan, and S. K. Kapoor, "Prevalence of common mental disorders among patients with diabetes mellitus and hypertension in an urban east Delhi slum-a cross-sectional study," Telangana Journal of Psychiatry, vol. 1, no. 1, pp. 27-32, 2015.

[24] A. Thour, R. Nagra, A. Gosal, T. Sehrawat, S. Das, and Y. Gupta, "Anxiety among patients with diabetes mellitus evaluated using generalized anxiety disorder 7-item scale," Journal of Social Health and Diabetes, vol. 4, no. 2, pp. 133136, 2016.

[25] A. Ahmad, M. Abujbara, H. Jaddou, N. A. Younes, and K. Ajlouni, "Anxiety and depression among adult patients with diabetic foot: prevalence and associated factors," Journal of Clinical Medicine Research, vol. 10, no. 5, pp. 411-418, 2018.

[26] Z. Chapman, C. M. J. Shuttleworth, and J. W. Huber, "High levels of anxiety and depression in diabetic patients with charcot foot," Journal of Foot and Ankle Research, vol. 7, no. 1, p. 22, 2014.

[27] M. W. Sweileh, M. H. Abu-Hadeed, W. S. Al-Jabi, and H. S. Zyoud, "Prevalence of depression among people with type 2 diabetes mellitus: a cross sectional study in Palestine"” BMC Public Health, vol. 14, p. 163, 2014.

[28] A. A. Al-Mohaimeed, "Prevalence and factors associated with anxiety and depression among type 2 diabetes in Qassim: a descriptive cross-sectional study," Journal of Taibah University Medical Sciences, vol. 12, no. 5, pp. 430-436, 2017.

[29] R. Mohamed, A. A. Kadir, and L. H. Yaacob, "A study on depression among patient with type 2 diabetes mellitus in North-Eastcoast Malaysia," International Journal of Collaborative Research on Internal Medicine \& Public Health, vol. 4, no. 8, pp. 1589-1600, 2012.

[30] R. J. Anderson, K. E. Freedland, R. E. Clouse, and P. J. Lustman, "The prevalence of comorbid depression in adults with diabetes: a meta-analysis," Diabetes Care, vol. 24, no. 6, pp. 1069-1078, 2001.

[31] R. M. Al-Amer, M. M. Sobeh, A. A. Zayed, and H. A. AlDomi, "Depression among adults with diabetes in Jordan: risk factors and relationship to blood sugar control," Journal of Diabetes and Its Complications, vol. 25, no. 4, pp. 247-252, 2011.

[32] S. K. Chaturvedi, S. Manche Gowda, H. U. Ahmed et al., "More anxious than depressed: prevalence and correlates in a 15-nation study of anxiety disorders in people with type 2 diabetes mellitus," General Psychiatry, vol. 32, Article ID e100076, 2019.

[33] L. E. Edwards and B. Mezuk, "Anxiety and risk of type 2 diabetes: evidence from the Baltimore epidemiologic catchment area study," Journal of Psychosomatic Research, vol. 73, no. 6 , pp. 418-423, 2012. 